\title{
NON-AGENDA
}

With the view of causing an increase to take place in the mass of national wealth, or with a view to increase of the means either of subsistence or enjoyment, without some special reason, the general rule is, that nothing ought to be done or attempted by government. The motto, or watchword of government, on these occasions, ought to be - Be quiet...Whatever measures, therefore, cannot be justified as exceptions to that rule, may be considered as non-agenda on the part of government.

— Jeremy Bentham (c.1801)

\section{Indigenous Employment Forecasts: Implications for Reconciliation}

\section{Boyd Hunter and John Taylor}

$\longrightarrow$ urrent government policy seeks to achieve 'practical reconciliation' between Indigenous and other Australians by focusing on closing the gap in the key social policy areas of health, housing, education and employment. Reflecting on progress to date, Altman and Hunter (2003) have analysed a range of Indigenous socioeconomic outcomes over the reconciliation decade of 1991 to 2001 concluding that there is little statistical evidence so far from census information to indicate a narrowing of the gap in the manner sought.

This finding is of interest as it reflects the net impact of Indigenous social and economic policy settings enacted during the years of the Hawke and Keating governments in the first half of the 1990s, and then of the first two Howard administrations from 1996 to 2001. Very briefly, from a labour market perspective, such initiatives (chronologically) included the establishment of Indigenous training and job programs under the Aboriginal Employment Development Policy (AEDP), then their enhancement under the Working Nation initiative, followed by the dismantling of Working Nation and associated privatisation of employment services, and most recently the revitalisation of dedicated Indigenous labour market programs under the Indigenous Employment Policy (IEP).

Over this same decade the Australian labour market underwent significant structural and compositional change. In general, the income distribution in Australia has tended to become more unequal over the last 15-20 years, a trend also observed in many other OECD countries (Saunders, 2003). Other trends in labour markets - shift to the private sector, casual jobs and part-time work, as

Boyd Hunter and John Taylor are Fellow and Senior Fellow respectively in the Centre for Aboriginal Economic Policy Research at The Australian National University. 
well as ongoing secular increases in female labour force participation, dual-earner families, and long-term unemployment (Borland, 2003) - have also tended to exacerbate economic inequality. In the context of Indigenous Australia, the rise of 'mutual obligation' based welfare regimes, such as the work-for-the-dole scheme and the Community Development Employment Projects (CDEP) scheme, are also profoundly significant (Hunter, 2004). Under the CDEP scheme, Indigenous community organisations receive an allocation of similar magnitude to their collective unemployment benefit entitlement to undertake community defined 'work'.

Against the background of these policy and structural changes, the labour force status of Indigenous Australians has been routinely tracked with predictions made about likely outcomes in terms of employment and unemployment levels and rates (Taylor and Altman, 1997; Taylor and Hunter, 1998). In building a prognosis for Indigenous labour force status at the end of the present decade, this paper revisits these various predictions and considers their accuracy against observed outcomes. The essential finding is that aggregate labour market outcomes for Indigenous people during the 1990s were reasonably predictable, notwithstanding administrative shifts in government employment policies, major restructuring of the labour market, and a self-identified Indigenous population that expanded substantially mostly by the social ascription of individuals whose socioeconomic status is ultimately unknown. It is argued here that this assessment of predictability in Indigenous labour market outcomes provides a sound basis for developing further projections as a guide to likely future outcomes. First, though, the case needs to be established.

\section{Demographic Issues and Forecasting}

During the 1990s, or more precisely the ten years leading up to the 2001 Census, the census-based estimate of the Indigenous working-age population rose by 35 per cent from 208,000 to 280,000. This increase was substantially above the contribution from natural increase and it reflected, for whatever reason, growing inclusion in the census population of individuals who were not previously recorded as Indigenous. Obviously, with a population expanding by social ascription as much as by demographic factors, questions arise as to the potential for compositional change due to possible bias in the socioeconomic status of new entrants. While there is no means of assessing this directly, proxy measures have been developed for North American Indians (Eschbach, Supple and Snipp, 1998) and, in similar fashion, Hunter (1998) traced changes in the educational characteristics of single-year cohorts of Indigenous Australians between 1986 and 1996 on the understanding that if the composition of the cohort altered over time, then this would manifest itself as apparent change in the characteristics of the cohort. Fixed effect regression models of time-invariant 'age left school' variables were estimated on a 'synthetic' panel of Indigenous and non-Indigenous cohorts between 1986 and 1996. The null hypothesis of compositional change 
was rejected for all cohort groups. That is, the characteristics of the respective cohorts did not to change significantly over this period.

While this finding provides some basis for an assumption of stability in socioeconomic characteristics in spite of demographic change, a more tangible transformation of the Indigenous population in the second half of the twentieth century, and one that appears potentially more significant from the point of view of possible impacts on aggregate labour force status, has been a shift in overall Indigenous population distribution from an emphasis on remote and rural areas towards the towns and cities of the south and east (Taylor, 2003a).

The proportion of the Indigenous population resident in urban areas rose from just over two-thirds in 1991 (67 per cent) to almost three-quarters in 2001 (74 per cent). Almost one-third of Indigenous Australians are now resident in major urban areas. While this is still substantially less than that for the overall Australian population (66 per cent), it nonetheless represents a marked increase from the 15 per cent of the Indigenous population counted in 1971. As this process of greater population counts in urban areas has unfolded, ipso facto the rural share of the population has continued to decline: down from 56 per cent in 1971 to almost one-quarter in 2001. However, it is significant for the present exercise that the key factor driving this spatial redistribution of the population has not been migration, though undoubtedly this has occurred. Rather it has been the increasing tendency over time for individuals in the more settled parts of the nation to identify in the census as Indigenous. Indeed, the evidence to support an overall migration of Indigenous people towards areas with more favourable labour markets is slim with as much movement away from cities as towards them, a finding that has been consistently reported since the 1980s (Gray, 1989; Taylor and Bell, 1999). Thus, while the Indigenous population is increasingly recorded in areas with established labour markets this has not been due to migration, nor has it had any apparent distorting effect on overall labour force status or our ability to predict aggregate labour force status as will be demonstrated.

\section{Evaluating Recent Forecasts of Indigenous Labour Force Status}

In 1997, ATSIC commissioned a report, The Job Ahead, by the Centre for Aboriginal Economic Policy Research (CAEPR). That report estimated the fiscal costs to government of Indigenous employment disparity and provided a measure of the number of future additional jobs required to reduce the gap in labour force status (Taylor and Altman, 1997). The projections of working age in that report (ABS/CAEPR, 1996) were based on 1991 Census data, while employment trends covered the period from the 1986 Census to the 1994 National Aboriginal and Torres Strait Islander Survey (NATSIS). Following the release of 1996 Census data and the subsequent upward revision of population projections, these estimates of future employment numbers and job needs were revised, with the title of the resulting paper, The Job Still Ahead, indicative of the key findings (Taylor and Hunter, 1998). Hunter and Taylor (2001a) provided revised forecasts because the Spicer Review of the CDEP scheme induced policy changes that changed the 
likely projections of Indigenous labour force status. Results from the 2001 Census are now available and provide a basis for re-estimating future outcomes and evaluating previous forecasts for 2001.

Table 1: Validating Forecast Estimates of Labour Force Status of Indigenous Australians, 2001

\begin{tabular}{lcccc}
\hline & $\begin{array}{c}\text { Job Ahead: } \\
\text { Hunter and } \\
\text { Taylor (1997) }\end{array}$ & $\begin{array}{c}\text { Job Still Ahead: } \\
\text { Hunter and } \\
\text { Taylor (1998) }\end{array}$ & $\begin{array}{c}\text { Hunter and } \\
\text { Taylor (2001a) }\end{array}$ & 2001 Census \\
\hline Employment population ratio & 36.2 & 39.8 & 42.1 & 40.4 \\
$\begin{array}{l}\text { Mainstream Employment } \\
\text { (non-CDEP/Adult population) }\end{array}$ & 26.4 & 29.1 & 29.1 & 29.5 \\
CDEP/Adult population & 9.8 & 10.7 & 13 & 10.9 \\
Unemployment rate & 37.4 & 24.5 & 20.0 & 20.0 \\
Participation rate & 57.9 & 52.7 & 52.7 & 52.1 \\
\hline
\end{tabular}

Note: CDEP estimates for 2001 are based on administrative data because of the incomplete geographic coverage of the CDEP question in the 2001 Census. In any case, there was no data on the extent of CDEP scheme employment in the 1991 Census.

Table 1 presents these recent forecasts of Indigenous labour force status with a view to evaluating the performance of estimates based on population projections. The original Job Ahead was mostly based on 1991 Census data, while The Job Still Ahead and Hunter and Taylor (2001a) were based on 1996 Census data. However, the 1994 NATSIS was also used to estimate labour force participation in The Job Ahead, and administrative data from ATSIC was used to estimate the number employed in the CDEP scheme in all forecasts. The accuracy of projections depends on the reliability and source of data used in the forecasts.

For example, Hunter and Taylor (2001a) assumed higher CDEP employment than The Job Still Ahead because the Spicer Review marked a policy shift by which all CDEP participants were expected to be employed. However, the 2001 'Census' estimate of CDEP scheme employment was lower than in Hunter and Taylor (2001a) because ATSIC identified non-Indigenous participants in the scheme for the first time in that year. There were also some minor adjustments to the planned expansion in CDEP scheme places around this time. This overestimate of the number of CDEP jobs resulted in a rather high employmentpopulation ratio in Hunter and Taylor (2001a).

Notwithstanding, predictions about mainstream (non-CDEP employment have been reasonably accurate, especially for those forecasts based on 1996 Census data. The only substantial difference between the actual 2001 employment population ratio and the forecast was for the Job Ahead, which underestimated the eventual outcome by 3.1 percentage points. Given that the 
CDEP-population ratio in that publication underestimated the actual outcome by 1.1 percentage points, 2.0 percentage points of the differential were attributable to the shortfall in employment forecasts. In a sense, this shortfall is understandable in that the employment projection for The Job Ahead was based around the 1991 Census and hence failed to take into account either the historically large growth in Indigenous identification during the 1990s or the sustained period of macroeconomic growth. Neither of these conditions are likely to be repeated in the next ten years given that both variables are coming from a reasonably high base (for example, the economy is operating close to full capacity).

The assumption about labour force participation is particularly important when estimating unemployment rates. For example, Hunter and Taylor (2001b) demonstrate that NATSIS data systematically overestimate both unemployment and participation rates relative to census data. Consequently, The Job Ahead, which based its assumptions about participation on NATSIS data, produced relatively high unemployment forecasts for 2001 (37.4 per cent). The 2001 unemployment rate would have been 31.3 per cent if participation rates had not been over-estimated by using NATSIS data. Even if The Job Ahead had accurately predicted employment growth to 2001, the unemployment rate would have been 24.5 per cent (given participation rates in the 1991 Census). That is, about half of the over-estimated unemployment rates in that paper was due to the use of an incompatible data source on labour force participation. The essential message here is that as long as predictions are based on a consistent data source (that is, census data), forecasts will be reasonably robust. Indeed, the unemployment rate estimated for 2001 in Hunter and Taylor (2001a) was accurate to three decimal places.

\section{Future Size of the Working-age Population}

The future size of the population is estimated by the conventional means of applying a cohort component projection to the 2001 post-census estimate of the Indigenous population $(458,520)$. This is done using calculations of survivorship and fertility based on the most recent analysis of 2001 Census data (Kinfu and Taylor, 2002) and held constant for the projection period. In line with previous low series experimental projections of the Indigenous population produced by the ABS, no allowance is made for non-demographic additions or losses to the population. In other words, the Indigenous population is assumed to be affected only by natural increase. It should be noted that this last assumption produces population estimates at the lower end of expectation given the recent experiences of large non-biological intercensal increases in the Indigenous population (Gray, 1997; Kinfu and Taylor, 2002). To this extent, the projections are conservative. The results of the projection are summarised in Table 2.

Overall, by the end of the present decade, the Indigenous population is projected to be more than 550,000. Notwithstanding high adult mortality, this shows that the Indigenous working-age population aged 15 and over will increase markedly both in number, and as a proportion of the total population. As with the 
population generally, the Indigenous population is also ageing, though from a more youthful base. Thus, by 2011, an extra 84,000 Indigenous people are expected to be of working-age - almost as many again as are now employed. Accordingly, the working-age share of the population will rise from 61 per cent in 2001 to 65 per cent by 2011.

Table 2: Projected Indigenous Population by Broad Age-group

\begin{tabular}{|c|c|c|c|}
\hline & 2001 & 2006 & 2011 \\
\hline Age Group & \multicolumn{3}{|c|}{ Numerical distribution } \\
\hline$<15$ & 178,692 & 184,715 & 193,029 \\
\hline $15^{+}$ & 279,828 & 320,497 & 363,577 \\
\hline \multirow[t]{2}{*}{ Total population } & 458,520 & 505,212 & 556,606 \\
\hline & \multicolumn{3}{|c|}{ Per cent distribution } \\
\hline$<15$ & 39.0 & 36.6 & 34.7 \\
\hline $15+$ & 61.0 & 63.4 & 65.3 \\
\hline
\end{tabular}

Source: Hunter, Kinfu and Taylor (2003).

\section{Projecting Labour Force Status, 2001-11}

As for labour force dynamics we refine some of the cruder assumptions made in earlier analyses (Taylor and Altman, 1997; Taylor and Hunter, 1998), for example by allowing Indigenous employment in the private sector in full-time work, and in all jobs, to grow at different rates. We also include an estimate of the effect of large numbers of discouraged Indigenous workers on our forecasts. A discouraged worker is someone who has given up looking for work, for example because there are no jobs available for them in the local area (Hunter and Gray, 2001). Aside from these changes the methodology and rationale, in terms of benchmarking current labour market outcomes and foreshadowing future ones, remains the same as that in other recent forecasts of Indigenous labour force status.

The key to projecting labour force status is to first establish estimates of the future size of the Indigenous labour force. This is done by assuming that the labour force participation rate remains at the level recorded by the 2001 Census which is the most recent indicator of Indigenous labour supply. The empirical basis for adopting this assumption is the fact that the Indigenous participation rate has remained relatively steady for the past decade at around 52 per cent. Using our projections of the Indigenous working-age population to 2011, age-specific participation rates from the 2001 Census may then be applied to derive estimates of labour force numbers, as shown in Table 3. 
Table 3: Projected Estimates of Indigenous Employment, Labour Force and Working-age Population.

\begin{tabular}{lccccc}
\hline & $\begin{array}{c}\text { Mainstream }^{a} \\
\text { employment }^{a}\end{array}$ & $\begin{array}{c}\text { CDEP } \\
\text { employment }^{b}\end{array}$ & $\begin{array}{c}\text { Total } \\
\text { employment }\end{array}$ & Labour force $^{c}$ & $\begin{array}{c}\text { Population } \\
15+\end{array}$ \\
\hline 2001 & 82,508 & 30,474 & 112,982 & 145,790 & 279,828 \\
2006 & 88,013 & 34,224 & 122,237 & 166,979 & 320,497 \\
2011 & 93,884 & 36,974 & 130,858 & 189,424 & 363,577 \\
\hline
\end{tabular}

Notes: a Mainstream based on continuation of 1996-2001 aggregate jobs growth of 1.3 per cent per annum for the Australian labour market.

b Based on an increase of 1,000 CDEP places in 2004 following 2003 budget provisions, plus an assumption that CDEP participants increase by natural growth of 550 per annum after 2001.

c Labour force based on maintaining Labour Force Participation Rate at the 2001 level (52.1 per cent).

As for estimating numbers in employment, separate calculations are made for mainstream employment and employment in the Community Development Employment Projects (CDEP) scheme. For mainstream employment, it is assumed that this will continue to expand at the rate observed between 1996 and 2001 of 1.3 per cent per annum. In projecting CDEP scheme employment, policy and fiscal constraints provide the parameters for growth. On the basis of recent and current planning for the scheme, it is assumed that the number of participants will continue to expand beyond 2001 by 550 participants per annum according to program allowance for natural (administrative) increase in existing schemes, while an extra 1,000 participants are added in 2004 as per provisions in the 2003-04 Commonwealth budget.

Thus, Table 3 indicates that the number of employed CDEP scheme participants is expected to rise from 30,474 in 2001 to almost 37,000 by 2011 . Assuming that mainstream employment continues to grow at the rate observed in the last half of the 1990s, then this rises from 82,508 in 2001 to 93,884 in 2011. Accordingly, total employment is estimated to rise from 112,982 to around 131,000 .

In Table 4, these projected changes in employment numbers are converted to employment/population ratios and unemployment rates. Because the rate of employment growth is anticipated to be slower than population growth, the overall employment rate is expected to fall from 40 to 36 per cent over the projection period. Assuming no change in the labour force participation rate, the reverse side of this equation will see the unemployment rate rise from 22.5 per cent of those in the labour force to almost 31 per cent.

While these projections clearly point to a worsening in the labour force status of Indigenous adults, it must be noted that they are based on the inclusion of CDEP scheme participants in the estimates of persons employed. If these CDEP scheme workers were excluded, and instead counted as unemployed (on 
account of the notional link between CDEP wages and Newstart/Job Search Allowance), then predicted labour market outcomes for Indigenous people become far worse with an unemployment rate of 43 per cent in 2001 rising to 50 per cent by 2011. Even with the growth in CDEP scheme employment, Indigenous employment rates decrease by around five and four percentage points for overall and non-CDEP employment respectively. Thus, planned CDEP growth is currently insufficient to maintain the status quo and will lead to increased employment disparity under current projections.

\section{Table 4: Estimated Indigenous Employment/Population Ratios and} Unemployment Rates. ${ }^{\text {a }}$

\begin{tabular}{|c|c|c|c|}
\hline & \multicolumn{3}{|c|}{ Census } \\
\hline & 2001 & 2006 & 2011 \\
\hline \multicolumn{4}{|c|}{ Employment/population ratios } \\
\hline Total employment $^{\mathrm{b}}$ & 40.4 & 38.1 & 36.0 \\
\hline Non-CDEP employment & 29.5 & 27.5 & 25.8 \\
\hline \multicolumn{4}{|c|}{ Unemployment rates } \\
\hline CDEP counted as employed & 22.5 & 26.8 & 30.9 \\
\hline CDEP counted as unemployed & 43.4 & 47.3 & 50.4 \\
\hline \multicolumn{4}{|c|}{ Unemployment rates when discouraged workers included in labour force ${ }^{c}$} \\
\hline $\begin{array}{l}\text { CDEP counted as employed and ABS definition of } \\
\text { discouraged workers }\end{array}$ & 25.9 & 30.0 & 33.9 \\
\hline $\begin{array}{l}\text { CDEP counted as unemployed and ABS definition of } \\
\text { discouraged workers }\end{array}$ & 45.9 & 49.6 & 52.6 \\
\hline $\begin{array}{l}\text { CDEP counted as unemployed and all people who want } \\
\text { work are included in labour force }\end{array}$ & 55.9 & 58.9 & 61.3 \\
\hline
\end{tabular}

Notes: a Estimates based on post-2001 Census population estimates and projections as shown in Table 2.

b Includes those employed in the CDEP scheme. All of the estimates are based on the data in Table 3. Unemployment rates express the unemployed as a percentage of the labour force.

c The ABS definition of discouraged worker is confined to those who are available to start work and give a reason for not actively looking for work that is related to the supply of jobs or other demand side reasons. Gray, Heath and Hunter (2002) argue that effective labour supply may include all those who want to work because their behaviour is similar to that of the unemployed for the Australian population as a whole.

The second panel in Table 4 includes a calculation of unemployment rates when discouraged workers are included in the labour force. Note that these rates are significantly higher when discouraged workers are included. They are even higher still if all people who want work are included in the labour force. Within 
this hypothetical framework, Indigenous unemployment rates would be as high as 61 per cent by 2011.

It is worth recalling that the equivalent rates for the rest of the Australian population are presently around 6.0 per cent for unemployment. On past experience, and present Budget forecasts, these are likely to remain relatively unchanged (Commonwealth of Australia, 2003). For example, the Commonwealth Budget confidently predicts that further jobs should be created next year, and that the unemployment rate should remain steady at around current low levels. The medium-term prognosis then, all other things being equal, is for a substantial worsening of the overall labour force status of Indigenous people both relatively and absolutely.

\section{Future Employment Requirements}

Using the projected estimates of employment it is possible to calculate the number of jobs required for Indigenous people to maintain the status quo in employment status or achieve an equivalent rate of employment to the non-Indigenous population.

As indicated in Table 4, the 2001 employment/population ratio for Indigenous people is estimated at 40.4 per cent. This was substantially below the ratio of 58.9 per cent recorded by the Census for all other Australians. Assuming that the estimated base Indigenous employment of 112,982 persons is not eroded in future, and that the non-Indigenous employment/population ratio also remains constant, two sets of estimated employment requirements are provided in Table 5:

- a minimalist scenario which indicates the numbers required simply to maintain the Indigenous employment/population ratio at its 2001 level; and

- the numbers required to achieve an employment rate equivalent to that of the rest of the population.

Table 5: Required Indigenous Employment Growth to Maintain the Status Quo or to Achieve Employment Equality, 2001-11.

\begin{tabular}{|c|c|c|c|c|c|}
\hline $\begin{array}{c}\text { Employment/ } \\
\text { Population } \\
\text { ratio }\end{array}$ & $\begin{array}{c}\text { Base } \\
\text { employment } \\
2001^{a}\end{array}$ & $\begin{array}{c}\text { Total jobs } \\
\text { required } \\
\text { by } 2011\end{array}$ & $\begin{array}{l}\text { Extra } \\
\text { jobs } \\
\text { required }\end{array}$ & $\begin{array}{c}\text { Extra } \\
\text { jobs } \\
\text { projected }^{b}\end{array}$ & $\begin{array}{c}\text { Projected } \\
\text { jobs deficit } \\
\text { by } 2011\end{array}$ \\
\hline $40.4^{c}$ & 112,982 & 146,885 & 33,903 & 17,876 & 16,027 \\
\hline $58.9^{d}$ & 112,982 & 214,147 & 101,164 & 17,876 & 83,289 \\
\hline
\end{tabular}

Notes: a The estimated number of Indigenous Australians in employment in 2001.

b From Table 3.

c Estimated employment/population ratio for Indigenous Australians based on 2001 population estimates.

d The employment/population ratio for non-Indigenous Australians from the 2001 Census. 
Because of growth in the population of working age, an additional 33,903 jobs will be required by the year 2011 just to maintain the rate of Indigenous employment at the 2001 level. This means that by the end of the decade, the Indigenous workforce will need to have increased by almost one-third of its estimated present size to avoid any decline in the already low employment level.

However, achieving employment equality between Indigenous and nonIndigenous Australians by the end of the next decade will require many more new jobs. By the year 2011 a total of 101,000 additional jobs will be required, an increase almost equivalent to the current size of the workforce. In annual terms, this translates into more than 10,000 new jobs per annum, which is substantially greater than the 3,362 new jobs estimated to have been created each year in the last half of the 1990s. Given current trends in employment growth, the projected shortfall in jobs for Indigenous people, using non-Indigenous employment levels as a benchmark, is around 83,000. Given the scale of this job deficit, it should be noted that these employment outcomes represent a best-case scenario as they include CDEP scheme participants.

\section{Implications for Reconciliation}

This analysis of 2001 Census data reveals no improvement in the overall position of Indigenous people in the labour market since 1996. Looking ahead, our estimates of future job growth point to a lowering of employment rates and rising unemployment over the remainder of this decade. Overall, the current fiscal cost of this failure to eradicate Indigenous employment disparity is massive — in 2001, it was estimated to be around 0.5 per cent of Australian GDP (Hunter and Taylor, 2002). Clearly, failure to achieve reconciliation already imposes a heavy fiscal burden on government and the results confirm previous findings that the burden will escalate in the future in proportion to the newly calibrated unemployment levels.

While it is not possible to put a dollar value on less tangible social costs of low employment and high unemployment, research has shown that the Indigenous unemployed, especially the long-term unemployed, fare worse than the employed on a range of social indicators - in terms of higher rates of arrest and police harassment, and lower levels of social capital and civic engagement (Hunter and Taylor, 2002).

Thus, a vital issue for policy in the years ahead is the distinct prospect that the overall situation for Indigenous people will continue to deteriorate. This is primarily because of population growth, but also because of the enormous difficulties of economic catch-up in a rapidly changing, skills-based, and competitive labour market. Furthermore, many of the structural factors undermining Indigenous participation in the labour market remain in place locational disadvantage, poor human capital endowments, and social exclusion. In short, we find no reason to retract, or alter, any of the policy implications and contributory factors leading to Indigenous disadvantage in the labour market that 
were outlined in previous such analyses - The Job Ahead (Taylor and Altman, 1997), and The Job Still Ahead (Taylor and Hunter, 1998).

Currently, the feedback between social exclusion and employment status is prominent in public debate. The prevalence of community dysfunction, manifest in domestic violence, substance abuse and accompanying recidivism, is an issue that most concerns many Aboriginal leaders (Ah Kit, 2002; Pearson, 2000a; Pearson, 2000b). While resolution of such issues may well involve new forms of Indigenous governance and leadership, as Pearson proposes, there is also debate about the capacity of Indigenous groups to institute reforms unassisted, and about whether the involvement of government in engineering social change might not carry its own risks (Martin, 2001).

Whatever the outcome stemming from this debate, it is our contention that there will remain a need for the Indigenous unemployed to be better informed about, and better able to engage with, employment opportunities in the mainstream economy (inter alia through greater access to outward looking networks). While Indigenous people may be seen as rich in social capital, this may reflect an excessive reliance on inward looking networks (Hunter, 2000). Equally, the relative educational status of Indigenous people needs to improve so that a wider range of jobs are accessible to them. Structural issues such as the buoyancy of the local economy in regional Australia, where many Indigenous people live, will also need to be addressed.

Employment in the public and community sectors will remain vital to Indigenous labour force participation, but it has been the private sector, albeit starting from a low base, that has been the engine of growth in Indigenous employment in recent years. This relative success coincides with the implementation of the Indigenous Employment Program (IEP). There are signs, then, that the IEP is effective in its aims, mainly through the provision of wage subsidies and the Structured Training Employment Program, though it should be noted that this is mainly in areas with established labour markets (Department of Employment and Workplace Relations, 2003). Indeed, the lack of evident impact in remote areas away from labour markets reinforces the need for flexible policy interventions (see Taylor, 2003b).

We can say with a high degree of confidence that the Indigenous Australian population will be at least 550,000 by the end of the present decade, and with far less confidence that it will approach 750,000 by 2021 . Furthermore, as with the Australian population generally, the future Indigenous population will be older in profile than it is now, with most growth occurring among those of working age. However, this ageing process will continue to lag far behind that underway among the rest of the population with the consequence that social and economic policy issues for Indigenous people will remain disproportionately focussed on the needs of youth and young families, as opposed to mainstream concerns which by then will be firmly focussed on the needs of the aged.

Demographic factors also have ongoing implications for Indigenous education policy settings for the foreseeable future. As with the other policy areas, extra expenditure on Indigenous education is required just to maintain the 
status quo. Even if the practical reconciliation agenda were sufficient to redress Indigenous disadvantage within the education system, the appropriate budget needs to expand at least in proportion with the size of the cohorts entering the relevant age groups. Hunter and Schwab (2003) note that the Indigenous cohort born between 1996 and 2001 appears to be smaller than other recent cohorts, and consequently the expenditure on Indigenous education required to maintain the status quo may possibly fall in about ten years time. Whatever the case, in benchmarking spending on Indigenous economic policy, and in navigating the path to reconciliation, there is clearly a need to take into account the fact of a rapidly expanding population base. Obviously it would be a mistake to deny the difficulties that policy makers face in the near future in attempting to achieve reconciliation. This paper outlines the likely scale of the job at hand and reemphasises the importance of demographic factors.

\section{References}

ABS/CAEPR (1996), 1994 National Aboriginal and Torres Strait Islander Survey: Employment Outcomes for Indigenous Peoples, Cat. No. 4199.0, ABS, Canberra.

Ah Kit, J. MLA (2002), Ministerial Statement from the Minister assisting the Chief Minister on Indigenous Affairs, Northern Territory Parliament, Darwin, available at: http://www.nt.gov.au/ocm/speeches/20020305_ahkit_aboriginal.shtml.

Altman, J. and B. Hunter (2003), 'Evaluating Indigenous Socioeconomic Outcomes in the Reconciliation Decade, 1991-2001’, Economic Papers 22(4):1-16.

Borland, J. (2003), 'Labour Market and Industrial Relations', pp. 94-117 in I. McAllister, S. Dowrick and R. Hassan (eds), The Cambridge Handbook of Social Sciences in Australia, Cambridge University Press, Cambridge.

Commonwealth of Australia (2003), Commonwealth Budget-Overview, Treasury, Canberra (available at: http://www.budget.gov.au/2003-04).

Department of Employment and Workplace Relations (2003), Indigenous Employment Policy Evaluation Stage Two: Effectiveness Report, Evaluation and Programme Performance Branch, EPPB Report 1/2003, Department of Employment and Workplace Relations, Canberra.

Eschbach, K., K. Supple, and M. Snipp (1998), 'Changes in Racial Identification and the Educational Attainment of American Indians, 1970-1990', Demography 35(1):1-9.

Gray, A. (1989), 'Aboriginal Migration to the Cities', Journal of the Australian Population Association 6(2):122-44.

Gray, A. (1997), 'The Explosion of Aboriginality: Components of Indigenous Population Growth 1991-96’, CAEPR Discussion Paper No. 142, CAEPR, Canberra.

Gray, M., A. Heath, and B. Hunter (2002), 'An Exploration of Marginal Attachment to the Australian Labour Market’, Reserve Bank Research Discussion Paper No. 2002/7, RBA, Sydney (available at http://www.rba.gov.au/). 
Hunter, B. (1998), 'Assessing the Validity of Intercensal Comparisons of Indigenous Australians, 1986-96’, Journal of the Australian Population Association 15(1):51-67.

Hunter, B. (2000), 'Social Exclusion, Social Capital and Indigenous Australians: Measuring the Social Costs of Unemployment', CAEPR Discussion Paper No. 204, CAEPR, Canberra.

Hunter, B. (2004), Indigenous Australians in the Contemporary Labour Market, ABS Cat. No. 2052.0, Canberra.

Hunter, B. and M. Gray (2001), 'Indigenous Labour Force Status Re-visited: Factors Associated with the Discouraged Worker Phenomenon', Australian Journal of Labour Economics 4(2):115-37.

Hunter, B., Y. Kinfu and J. Taylor (2003), 'The Future of Indigenous Work: Forecasts of Labour Force Status to 2011', CAEPR Discussion Paper No. 251, CAEPR, ANU, Canberra (available at: http://online.anu.edu.au/caepr/).

Hunter, B. and R. Schwab (2003), 'Practical Reconciliation and Recent Trends in Indigenous Education’, CAEPR Discussion Paper No. 249, CAEPR, ANU, Canberra.

Hunter, B. and J. Taylor (2001a), 'Indigenous Jobs Growth and Unemployment, 19962006: The Impact of CDEP’, Australian Journal of Labour Economics 4(2):65-76.

Hunter, B. and J. Taylor (2001B), 'The Reliability of Indigenous Employment Estimates', Agenda 8(2):113-28.

Hunter, B. and J. Taylor (2002), 'An Overview of the Costs of Indigenous Unemployment', pp. 109-33 in P. Saunders and R. Taylor (eds), The Price of Prosperity, University of New South Wales Press, Sydney.

Kinfu, Y. and J. Taylor (2002), 'Estimating the Components of Indigenous Population Change: 1996-2001’, CAEPR Discussion Paper No. 240, CAEPR, Canberra.

Martin, D. (2001), 'Is Welfare Dependency “Welfare Poison”? An Assessment of Noel Pearson's Proposals for Aboriginal Welfare Reform', CAEPR Discussion Paper No. 213, CAEPR, Canberra.

Pearson, N. (2000a), Our Right to Take Responsibility, Noel Pearson and Associates, Cairns.

Pearson, N. (2000b), 'Strong Families, then Strong Communities', Address to the Indigenous Families and Communities Roundtable, Canberra, October 24, transcript available at: www.brisinst.org.au.

Saunders, P. (2003), 'Income Distribution and Redistribution', pp. 118-37 in I. McAllister, S. Dowrick and R. Hassan (eds), The Cambridge Handbook of Social Sciences in Australia, Cambridge University Press, Cambridge.

Taylor, J. (2003a), 'Indigenous Australians: The First Transformation', pp. 17-40 in S. Khoo and P. McDonald (eds), The Transformation of Australia's Population: 1970-2030, University of New South Wales Press, Sydney. 
Taylor, J. (2003b), 'Indigenous Economic Futures in the Northern Territory: The Demographic and Socioeconomic Background', CAEPR Discussion Paper No. 246, CAEPR, ANU, Canberra.

Taylor, J. and J. Altman (1997), 'The Job Ahead: Escalating Economic Costs of Indigenous Employment Disparity’, Office of Public Affairs, ATSIC, Canberra.

Taylor, J. and M. Bell (1999), 'Changing Places: Indigenous Population Movement in the 1990s’, CAEPR Discussion Paper No. 189, CAEPR, Canberra.

Taylor, J. and B. Hunter (1998), 'The Job Still Ahead: Economic Costs of Continuing Indigenous Employment Disparity’, Office of Public Affairs, ATSIC, Canberra.

A preliminary version of this paper was presented in seminars held at the ANU and the Department of Family and Community Services, both in Canberra, and at the Cranlana Program seminar, 'Pathways for Reconciliation', held in Melbourne on 4 and 5 September 2003. We are grateful for the feedback from those presentations. Thanks are also due to Jon Altman, Matthew Gray, Anne Daly and several anonymous referees. We are especially grateful to Yohannes Kinfu who provided substantial assistance in construction of the demographic forecasts for the Indigenous population. 